\title{
A new set of ESTs and CDNA clones from full-length and normalized libraries for gene discovery and functional characterization in citrus
}

\author{
M Carmen Marques ${ }^{1,2}$, Hugo Alonso-Cantabrana ${ }^{1,3}$, Javier Forment ${ }^{1}$, \\ Raquel Arribas ${ }^{1}$, Santiago Alamar ${ }^{1,4}$, Vicente Conejero ${ }^{1}$ and Miguel A Perez- \\ Amador*1
}

\begin{abstract}
Address: ${ }^{1}$ Instituto de Biología Molecular y Celular de Plantas (IBMCP), Universidad Politécnica de Valencia and Consejo Superior de Investigaciones Científicas (CSIC). Avenida de los Naranjos s/n, 46022 Valencia, Spain, ${ }^{2}$ Current address : Centro de Investigación Príncipe Felipe. Avenida Autopista del Saler 16, 46012 Valencia, Spain, ${ }^{3}$ Current address : Synergia Bionostra S.L. Ronda de Poniente 4, 28760 Tres Cantos, Madrid, Spain and ${ }^{4}$ Current address : Instituto de Agroquímica y Tecnología de Alimentos (IATA), Consejo Superior de Investigaciones Científicas (CSIC), Burjassot, Valencia, Spain

Email: M Carmen Marques - mcmarques@cipf.es; Hugo Alonso-Cantabrana - halonso@synergiabio.com; Javier Forment - jforment@ibmcp.upv.es; Raquel Arribas - rarribas@iesibamar.com; Santiago Alamar - santiagoalamar@iata.csic.es; Vicente Conejero - vconejer@ibmcp.upv.es; Miguel A Perez-Amador* - mpereza@ibmcp.upv.es

* Corresponding author
\end{abstract}

\begin{abstract}
Background: Interpretation of ever-increasing raw sequence information generated by modern genome sequencing technologies faces multiple challenges, such as gene function analysis and genome annotation. Indeed, nearly $40 \%$ of genes in plants encode proteins of unknown function. Functional characterization of these genes is one of the main challenges in modern biology. In this regard, the availability of full-length cDNA clones may fill in the gap created between sequence information and biological knowledge. Full-length cDNA clones facilitate functional analysis of the corresponding genes enabling manipulation of their expression in heterologous systems and the generation of a variety of tagged versions of the native protein. In addition, the development of full-length cDNA sequences has the power to improve the quality of genome annotation.

Results: We developed an integrated method to generate a new normalized EST collection enriched in full-length and rare transcripts of different citrus species from multiple tissues and developmental stages. We constructed a total of I5 cDNA libraries, from which we isolated 10,898 high-quality ESTs representing 6/42 different genes. Percentages of redundancy and proportion of full-length clones range from 8 to 33, and 67 to 85 , respectively, indicating good efficiency of the approach employed. The new EST collection adds 2113 new citrus ESTs, representing I83I unigenes, to the collection of citrus genes available in the public databases. To facilitate functional analysis, cDNAs were introduced in a Gateway-based cloning vector for high-throughput functional analysis of genes in planta. Herein, we describe the technical methods used in the library construction, sequence analysis of clones and the overexpression of CitrSEP, a citrus homolog to the Arabidopsis SEP3 gene, in Arabidopsis as an example of a practical application of the engineered Gateway vector for functional analysis.

Conclusion: The new EST collection denotes an important step towards the identification of all genes in the citrus genome. Furthermore, public availability of the cDNA clones generated in this study, and not only their sequence, enables testing of the biological function of the genes represented in the collection. Expression of the citrus SEP3 homologue, CitrSEP, in Arabidopsis results in early flowering, along with other phenotypes resembling the over-expression of the Arabidopsis SEPALLATA genes. Our findings suggest that the members of the SEP gene family play similar roles in these quite distant plant species.
\end{abstract}




\section{Background}

Citrus is one of the most widespread fruit crops with great economic and health value [1]. But citrus is also one of the most difficult plants to improve through traditional breeding approaches due to undesirable reproductive traits and characteristics. These include degrees of sexual sterility and incompatibility, nucellar embryony (asexual seed production), extended juvenility, and large plant size, which affect cultural practice in the orchard. To overcome these drawbacks, new genomic approaches are being developed, including generation of linkage maps, markers, and EST collections, making possible physical and genetic mapping in citrus. Furthermore, an International Citrus Genomics Consortium (ICGC) has been initiated to generate the full-genome sequence of sweet orange (Citrus sinensis), as well as to sequence other citrus species and varieties [1]. Prior to the establishment of the ICGC, EST collections [2,3] have provided a first glimpse of the citrus genome. Over the years, several different groups have contributed to the generation of a total of over 230,000 citrus sequences currently deposited at the dbEST division of the GenBank. Among these, the Spanish Citrus Genomic Project (CFGP) http://bio info.ibmcp.upv.es/genomics/cfgpDB has made a significant contribution producing 25 standard cDNA libraries, an EST collection of 22,635 high-quality reads [4], and generating sequence data for over 54,000 ESTs from a normalized full-length cDNA library and 9 additional standard libraries [5]. EST sequencing along with other gene discovery methods, represent an important initial step towards functional characterization of the genes in the genome.

Many methods for the construction of cDNA libraries have been developed in recent years. Conventional cDNA library construction approaches, however, suffer from several major shortcomings. First, the majority of cDNA clones are not full-length, especially for mRNAs longer than $2 \mathrm{~kb}$. This loss of 5 -terminal sequences is typically due to premature termination of reverse transcription or blunt-end polishing of cDNA ends prior to subcloning. As a result, cDNA 5' ends are significantly underrepresented in cDNA libraries. Second, an adaptor-mediated cloning process is still a common approach for cDNA library construction, leading to up to $20 \%$ of undesirable ligation byproducts (chimeras) and inserts of non-mRNA origin (e.g., genomic DNA, mitochondrial DNA, ribosomal RNA, or adaptor dimers) [6]. In recent years, the annotation of genes has been greatly improved by the integration of full-length cDNAs produced by the community [7-10]. The importance of isolating full-length cDNA clones relies in the "value-added" features lacking in common ESTs. Full-length cDNAs define the limits of the transcriptional units and the coding region, and thus identify the immediate upstream basal promoter and enable sequence char- acterization of $5^{\prime}$ and $3^{\prime}$ untranslated regions (UTR). Furthermore, they provide a record of transcript diversity due to modifications of the primary pre-mRNA transcript, such as alternate promoter usage, alternative splicing, alternate polyadenylation, and RNA editing. On the other hand, cDNA libraries rich in full-length clones are a valuable tool for high-throughput gene function analysis [11].

A number of methods have been developed for cDNA library preparations enriched in full-length sequences [1218 ] with most of them based on the mRNA cap structure $[12,14,15]$. These methods require high quantities of starting material (20-100 $\mu \mathrm{g}$ of RNA) and complicated, multi-step manipulations of the cap structure of mRNA and cDNA intermediates, which often result in degradation of mRNA and isolation of short clones, no longer than $1.5 \mathrm{~kb}-$ long [6]. By improving one of these methods, Suzuki and co-workers obtained an average size of fulllength clones of $1.9 \mathrm{~kb}$ from lower amounts of starting mRNA $(5-10 \mu \mathrm{g})[16,19]$. The recently described SMART ${ }^{\mathrm{TM}}$ method exploits two intrinsic properties of Moloney murine leukaemia virus (MMLV) reverse transcriptase, reverse transcription and template switching, and thus yields larger average ORF size $[6,20]$. Moreover, directional cloning has been implemented by using $S f i$ endonuclease, whose variable target sequence allows for designing adaptors with non-complementary ends, thus avoiding their concatenation. As the SfiI recognition sequence is very rare in eukaryotic genomes, the use of SfiI also eliminates the need for methylation during cDNA synthesis [21].

The differential abundance of various transcripts in any particular cell type is a well recognized obstacle for the efficient high-throughput analysis of cDNA libraries [18]. Usually 10-20 abundant genes (present at several thousand mRNA copies per cell) account for at least $20 \%$ of the cellular mRNA mass, while several thousand of rare genes (each represented less than 10 mRNA copies per cell) may account for $20-40 \%$ of the mRNA mass [18]. Hence, straightforward random sequencing of clones from standard cDNA libraries is inefficient for discovering rare transcripts, owing to the repeated occurrence of intermediate and highly abundant cDNAs. Decreasing the prevalence of clones representing abundant transcripts by normalizing the cDNA before sequencing may significantly increase the efficiency of random sequencing and is essential for rare gene discovery $[22,23]$. The normalization process generally utilizes second-order reaction kinetics of re-association of denatured DNA, so that relative transcript concentrations within the remaining singlestranded cDNA fraction are equalized to a considerable extent. Most of the normalization methods described differ in the process of isolation of the single-stranded (ss) and double-stranded (ds) cDNA fractions but typically 
employ one or more of the following: hydroxylapatite columns, magnetic beads, digestion of the ds-molecules by restriction endonucleases or amplification of the ss fraction using suppression PCR [24]. One of the recently described method takes advantage of the properties of a particular nuclease, the DSN from the Kamchatka crab, to specifically cleave ds-DNA in both DNA-DNA and DNARNA duplexes, allowing for the separation of the normalized ss-fraction [24-26]. DSN is a thermo-stable enzyme active at $70^{\circ} \mathrm{C}$, and therefore, the degradation of the dsfraction is carried out at the same temperature as the renaturation of cDNA. This helps to avoid a non-specific hybridization of cDNA during the DSN treatment and, hence, minimizes the loss of transcripts prone to the formation of secondary structures. The remaining normalized ss-fraction is then amplified using PCR [24,25]. Suitable cDNA for this procedure should contain known flanking sequences for subsequent PCR amplification. Furthermore, to avoid the preference towards shorter products, a process of regulation of average length is recommended [27]. The use of this method requires that the adapter sequences form inverted terminal repeats $[25,27]$.

On the other hand, moving beyond gene discovery to understanding gene function is facilitated by the ability to easily express proteins in both homologous and heterologous biological contexts. The functional analysis of genes typically requires each ORF to be over-expressed or silenced, the purification of the expressed protein, production of antibodies, analysis of phenotypes, determination of intracellular localization, and analysis of interactions with other proteins. This entails engineering of multiple expression constructs for every gene of interest, which is time-consuming and laborious when using traditional ligase-mediated cloning, posing a technical barrier for high-throughput functional genomics or proteomics projects [28]. Hartley and co-workers described a method called recombinational cloning that exploits the accurate and site-specific recombination system utilized by bacteriophage lambda in order to shuttle sequences between plasmids bearing compatible recombination sites [29]. This technology, commercially termed Gateway $^{\mathrm{TM}}$ (Invitrogen), bypasses the need for traditional ligase-mediated cloning, provides high specificity and activity, while maintaining orientation of the transferred DNA segment and yielding a high proportion of desired clones [28-32].

We took advantage of the SMART ${ }^{\mathrm{TM}}$ protocol, the DSN nuclease, and the Gateway technology to maximize acquisition of full-length and rarely-expressed cDNAs (from various tissues and under different conditions), ready to use for functional analysis purposes. Herein, we describe the methods employed to generate a new citrus cDNA collection, giving rise to a new set of ESTs and unigenes. As a direct example of the practical application of our collection, we carried out the overexpression of a full-length cDNA clone for the CitrSEP gene in Arabidopsis. The resulting transgenic plants showed early flowering and curly leaves, phenotypes that are consistent with a role of CitrSEP as a bona fide citrus ortholog of the Arabidopsis SEP3 gene. The protocol utilized in this study has thus been proven to be successful for generating new EST collections to improve gene annotation and gene discovery by functional characterization.

\section{Results and Discussion}

\section{Full-length and normalized cDNA libraries}

The Spanish Citrus Genomic Project (CFGP) was initiated with the purpose of functional characterization of citrus genes. It has generated an EST collection from standard cDNA libraries covering a wide range of tissues and developmental stages, as well as biotic and abiotic stress conditions [4]. In addition, cDNA microarray platforms have also been created $[4,33]$. In this work, we wanted to enrich the EST collection with the addition of a significant number of full-length cDNA clones. With this objective we decided to use the SMART ${ }^{\mathrm{TM}}$ method, as it allowed us to obtain large ESTs with few steps and from small quantities of starting RNA. Furthermore, the subcloning advantages of the Gateway system, which allows a captured target sequence to be easily shuttled into a variety of destination vectors, provides great advantages for future functional analyses of the isolated gene. For that reason, we modified the pENTR1A vector in order to make it suitable for the directional cloning of citrus cDNAs. A detailed description of the construction of the Gateway-based pENTR-SfiI is shown in Methods and Additional File 1. The engineered pENTR-Sfil cloning vector proved to be a useful tool for the construction of the cDNA libraries as it rendered a very high cloning efficiency and almost all of the clones generated contained cDNA inserts introduced in the direct orientation as single inserts (data not shown).

We constructed a total of 15 cDNA libraries (Table 1) using the SMART ${ }^{\mathrm{TM}}$ method and the engineered Gatewaybased pENTR-SfiI cloning vector. In order to increase the proportion of full-length clones, we also performed a size selection of the cDNAs, by removing those cDNAs that were shorter than $1 \mathrm{~kb}$, presumably corresponding to partial cDNAs and/or cDNAs that could have already been isolated in our standard cDNA libraries constructed previously [4]. Since EST collections are hampered by the presence of cDNA clones corresponding to highly expressed genes, which limit the probability of isolation of new gene sequences, we decided to include a normalization step in the construction of 4 of the cDNA libraries to isolate ESTs corresponding to rare or low-expressed genes. In order to get wide transcriptome coverage, multiple libraries were constructed from leaves, roots, shoots, flowers, ovaries 
Table I: Plant material used in each individual cDNA library, either full-length or full-length and normalized.

\begin{tabular}{|c|c|c|c|c|}
\hline Library & Species & Treatment & Tissue & $\begin{array}{c}\text { Developmental } \\
\text { stage }\end{array}$ \\
\hline \multicolumn{5}{|c|}{ Full-length enriched libraries } \\
\hline AbioticLI & C clementina & Several abiotic stresses* & Leaves & Adult \\
\hline AbioticRI & Creshni & Several abiotic stresses* & Roots & Young \\
\hline BiotPhyRI & C aurantium & $\begin{array}{l}\text { Infection with the oomycete Phytophthora } \\
\text { citrophthora }\end{array}$ & Roots & Young \\
\hline CTVMacropI & C macrophylla & Infection with the Citrus tristeza virus (CTV) & Leaves & Adult \\
\hline CTVClemen I & C clementina & Infection with the Citrus tristeza virus (CTV) & Shoot & Adult \\
\hline CEVdCidrol & C medica & $\begin{array}{l}\text { Infection with the Citrus exocortis viroid } \\
\text { (CEVd) }\end{array}$ & Leaves & Adult \\
\hline HSVdMacrol & C macrophylla & Infection with HSVd & Leaves & Adult \\
\hline DevOvaryl & C clementina & Normal culture conditions & Ovaries & Adult \\
\hline RVDevelopI & C clementina & Normal culture conditions & Leaves, flowers, ovaries and apical meristems & Adult \\
\hline PostharvCl & C clementina & Cold stress over harvested fruit & Mature fruit (flavedo) & Adult \\
\hline PostharvPI & C clementina & Infection with the fungus Penicillium digitatum & Mature fruit (flavedo and albedo) & Adult \\
\hline \multicolumn{5}{|c|}{ Normalized and full-length enriched libraries } \\
\hline RVDevelopN & C clementina & Normal culture conditions & Leaves, flowers, ovaries and apical meristems & Adult \\
\hline StrClemenN & C clementina & $\begin{array}{l}\text { Several abiotic stresses* } \\
\text { Infection with the Citrus tristeza virus (CTV) }\end{array}$ & $\begin{array}{l}\text { Abiotic stress: Leaves } \\
\text { Biotic stress: Shoots }\end{array}$ & Adult \\
\hline StrCleopN & Creshni & $\begin{array}{l}\text { Several abiotic stresses* } \\
\text { Infection with the oomycete Phytophthora } \\
\text { citrophthora }\end{array}$ & Roots & Young \\
\hline PostharveN & C clementina & $\begin{array}{l}\text { Cold stress over harvested fruit } \\
\text { Infection with the fungus Penicillium digitatum }\end{array}$ & $\begin{array}{l}\text { Abiotic stress: Fruits (flavedo) } \\
\text { Biotic stress: Fruits (flavedo + albedo). }\end{array}$ & Adult \\
\hline
\end{tabular}

* water stress, salt stress, progressive salt stress, and iron chlorosis.

and fruits of different citrus species under different stress or developmental conditions (Table 1).

\section{EST collection}

A total number of 11,968 independent cDNA clones were randomly isolated from the $15 \mathrm{cDNA}$ libraries and singlepass sequenced from the 5 ' end of the clone to generate the EST collection (Table 2). After low-quality and vector trimming of raw sequences, a total number of 10,898 high-quality ESTs longer than $100 \mathrm{bp}$ were obtained. High-quality sequences were deposited in the dbEST division of GenBank (accession numbers FC868488FC870221， FC873874-FC876453， FC877373-FC8777779, FC920173-FC921754, FC923090-FC924869, and FC929840-FC932655). Size distribution analysis showed that, after trimming of vector and poor quality sequences, most ESTs (89\%) were longer than $600 \mathrm{bp}$, with an average sequence length of 673 nucleotides (Additional File 2A).

Since new sequences are to be incorporated with the previous CFGP collection, EST assembly was carried out together with the other ESTs obtained in the CFGP. It revealed that ESTs from our full-length libraries could be clustered in 2240 singletons and 3902 contigs, yielding a total number of 6142 putative unique transcripts or uni- genes (Table 2). This number of unigenes is probably an overestimation of the number of unique transcripts isolated, as failure to assemble ESTs from a single transcript can result from alternate splicing, sequence polymorphisms, sequencing errors, and non-overlapping ESTs. To estimate this internal redundancy, the 6142 putative unigenes were compared with each other using BLASTN. Sequences with at least $90 \%$ nucleotide identity over a minimum of $300 \mathrm{bp}$ covering at least $75 \%$ of one sequence were assumed to be derived from the same transcript or from different transcripts coming from the same gene (e.g., alternative splicing and polyadenylation), and were therefore clustered in super-contigs (see Methods). This analysis resulted in 4691 unigenes remaining as singletons and 1451 unigenes being clustered in 666 supercontigs, indicating that the minimal number of identified expressed genes was 5357.

The number of ESTs per contig ranged from 2 (1016 contigs) to 78 (one contig, corresponding to a lectin-related protein), while most contigs (83\%) contained 4 or fewer ESTs, and only 15 contigs ( $0.8 \%$ of total) included more than 20 EST sequences (Additional File 2B). ESTs that constitute large clusters partially overlap, thus allowing the reconstitution of the full-length sequence of genes without having to use expensive and labor-intensive 
Table 2: Characterization of CDNA citrus libraries.

\begin{tabular}{|c|c|c|c|c|c|c|c|c|c|c|c|c|c|c|}
\hline Library & Clones & $\begin{array}{r}\text { High } \\
\text { quality } \\
\text { ESTs }\end{array}$ & $\begin{array}{r}\text { Mean } \\
\text { EST } \\
\text { length }\end{array}$ & $\begin{array}{r}\begin{array}{r}\text { Singleto } \\
\text { ns }\end{array}\end{array}$ & Contigs & $\begin{array}{r}\text { Contigs } \\
\text { with } \\
2-3 \\
\text { reads }\end{array}$ & Unigenes & $\begin{array}{r}\text { Redunda } \\
\text { ncy } \\
(\%)\end{array}$ & $\begin{array}{l}\text { Library- } \\
\text { specific } \\
\text { unigenes }\end{array}$ & $\begin{array}{r}\text { Novelty } \\
(\%)\end{array}$ & $\begin{array}{l}\text { Full- } \\
\text { length } \\
\text { clones }\end{array}$ & $\begin{array}{r}\text { ESTs } \\
\text { with } \\
\text { ortholog } \\
\text { ue }\end{array}$ & Fullness & $\begin{array}{r}\text { Full- } \\
\text { length } \\
\text { library- } \\
\text { specific } \\
\text { unigenes }\end{array}$ \\
\hline \multicolumn{15}{|c|}{ Full-length enriched libraries } \\
\hline AbioticLI & 960 & $831(87)$ & 673 & 125 & 498 & $481(97)$ & 623 & 25 & 139 & 22 & 613 & 794 (96) & 77 & 46 \\
\hline AbioticRI & 960 & $903(94)$ & 667 & 157 & 531 & $514(97)$ & 688 & 24 & 168 & 24 & 698 & $853(94)$ & 82 & 49 \\
\hline BiotPhyRI & 960 & $919(96)$ & 681 & 364 & 401 & $389(97)$ & 765 & 17 & 407 & 53 & 515 & $752(82)$ & 68 & 31 \\
\hline $\begin{array}{l}\text { CTVMacr } \\
\text { opl }\end{array}$ & 480 & 447 (93) & 651 & 133 & 214 & $205(96)$ & 347 & 22 & 147 & 42 & 350 & $412(92)$ & 85 & 58 \\
\hline $\begin{array}{l}\text { CTVClem } \\
\text { enI }\end{array}$ & 480 & $453(94)$ & 682 & 62 & 327 & $324(99)$ & 389 & 14 & 63 & 16 & 329 & $426(94)$ & 77 & 48 \\
\hline $\begin{array}{l}\text { CEVdCidr } \\
\text { ol }\end{array}$ & 480 & $465(97)$ & 693 & 111 & 220 & $214(97)$ & 331 & 29 & 152 & 46 & 330 & $446(96)$ & 74 & 59 \\
\hline $\begin{array}{l}\text { HSVdMacr } \\
\text { ol }\end{array}$ & 480 & $406(85)$ & 654 & 116 & 209 & $201(96)$ & 325 & 20 & 128 & 39 & 281 & $373(92)$ & 75 & 62 \\
\hline $\begin{array}{l}\text { DevOvary } \\
\text { I }\end{array}$ & 384 & $296(77)$ & 637 & 27 & 192 & $185(96)$ & 219 & 26 & 29 & 13 & 251 & 291 (98) & 86 & 69 \\
\hline $\begin{array}{l}\text { RVDevelo } \\
\text { pl }\end{array}$ & 960 & 759 (79) & 669 & 60 & 451 & $433(96)$ & 511 & 33 & 65 & 13 & 612 & 737 (97) & 83 & 46 \\
\hline $\begin{array}{l}\text { PostharvC } \\
\text { I }\end{array}$ & 960 & 917 (96) & 697 & 134 & 582 & $565(97)$ & 716 & 22 & 137 & 19 & 706 & $886(97)$ & 80 & 44 \\
\hline $\begin{array}{l}\text { PostharvP } \\
\text { I }\end{array}$ & 1056 & $1008(95)$ & 684 & 161 & 640 & $624(98)$ & 801 & 21 & 169 & 21 & 662 & $966(96)$ & 69 & 44 \\
\hline TOTAL & 8160 & 7404 (9I) & & 1450 & 2914 & & 4364 & & 1604 & 37 & 5347 & $6936(94)$ & 78 & 556 \\
\hline
\end{tabular}

\begin{tabular}{|c|c|c|c|c|c|c|c|c|c|c|c|c|c|c|}
\hline \multicolumn{15}{|c|}{ Normalized and full-length enriched libraries } \\
\hline $\begin{array}{l}\text { RVDevelo } \\
\text { pN }\end{array}$ & 960 & $823(86)$ & 640 & 182 & 543 & $540(99)$ & 725 & 12 & 192 & 26 & 560 & 755 (92) & 74 & 44 \\
\hline $\begin{array}{l}\text { StrClemen } \\
\mathrm{N}\end{array}$ & 960 & $866(90)$ & 658 & 186 & 567 & $563(99)$ & 753 & 13 & 203 & 27 & 544 & $810(94)$ & 67 & 45 \\
\hline $\begin{array}{l}\text { StrCleop } \\
N\end{array}$ & 960 & $914(95)$ & 693 & 246 & 594 & $594(100)$ & 840 & 8 & 254 & 30 & 655 & $866(95)$ & 76 & 51 \\
\hline $\begin{array}{l}\text { Postharve } \\
\mathrm{N}\end{array}$ & 928 & 891 (96) & 684 & 176 & 561 & $552(98)$ & 737 & 17 & 185 & 25 & 636 & 840 (94) & 76 & 41 \\
\hline TOTAL & 3808 & 3494 (92) & & 790 & 1882 & & 2672 & & 834 & 31 & 2395 & 327 I (94) & 73 & 181 \\
\hline $\begin{array}{l}\text { BIG } \\
\text { TOTAL }\end{array}$ & 11968 & $\begin{array}{r}10898 \\
(91)\end{array}$ & 673 & 2240 & 3902 & & 6142 & & 2438 & 40 & 7742 & $\begin{array}{r}10207 \\
(94)\end{array}$ & 76 & 737 \\
\hline
\end{tabular}


primer walking sequencing. These redundant sequences are also a source of single nucleotide polymorphisms (SNPs) for molecular marker development, and 233 contigs were found to have putative SNPs (data not shown).

\section{Improvement of the previous CFGP citrus EST collection}

We estimated the contribution of our new EST collection to the previous CFGP EST collection by calculating the redundancy and novelty of the full-length libraries constructed in this study. Table 2 shows the distribution per library of the number of ESTs, singletons, contigs, and unigenes, as well as the absolute and relative values for redundancy and novelty. Since we are interested in the optimization of the sequencing effort for the entire project, redundancy for each library was calculated as the percentage of ESTs in this library that correspond to unigenes already obtained in the whole project. Although this number is necessarily higher than redundancy within the library, most libraries ( 11 out 15 ) had a level of redundancy below $25 \%$, while in the most redundant library it was higher (33\%) but still acceptable. On the other hand, novelty was calculated as the percentage of unigenes in each library that have been isolated only from that particular library (unique unigenes). This number represents the level of uniqueness of the library, which can also be considered as an estimation of the capacity of the library to provide new genes to the collection, or gene discovery. The full-length libraries constructed in this study have novelty range of $13-53 \%$, with only 4 libraries having a novelty lower than $20 \%$ and three of them exceeding $40 \%$ (Table 2). The contribution of the full-length libraries to the whole citrus EST collection is therefore indicated by the low levels of redundancy and high percentages of novelty of these libraries. A major advantage of EST sequencing from multiple libraries is that it increases the possibility of identifying genes that are putatively transcribed specifically within a certain tissue, during a particular developmental phase, or under some environmental conditions. Our analysis indicates that 2438 unigenes (24\% of 6142) are specific for the newly constructed libraries, despite the presence of 85,965 ESTs in the entire CFGP collection, suggesting the utility of these new libraries.

We also compared the new citrus ESTs with the ESTs and unigenes already available in the Citrus HarvEST database, which contains 229,570 ESTs. We estimate that the new EST collection adds 2113 new citrus ESTs representing 1831 unigenes (Additional File 3). In other words, around $20 \%$ of ESTs and $30 \%$ of unigenes generated were not previously available in the public database and therefore represent new genes.
Table 3: Distribution of citrus and Arabidopsis genes according to the GO categories of Biological process.

\begin{tabular}{lll}
\hline GO category & Citrus & TAIR \\
\hline transport & & \\
protein modification process & 8.41 & 4.43 \\
translation & 6.47 & 3.50 \\
carbohydrate metabolic process & 5.49 & 3.07 \\
catabolic process & 4.58 & 2.00 \\
transcription & 4.28 & 1.50 \\
amino acid and derivative metabolic process & 4.08 & 4.21 \\
response to stress & 3.94 & 1.21 \\
cellular component organization and biogenesis & 3.81 & 4.77 \\
lipid metabolic process & 2.95 & 3.05 \\
cell communication & 2.36 & 1.72 \\
generation of precursor metabolites and energy & 2.29 & 2.74 \\
signal transduction & 2.24 & 0.52 \\
secondary metabolic process & 2.21 & 2.41 \\
response to abiotic stimulus & 1.92 & 0.83 \\
photosynthesis & 1.55 & 2.79 \\
response to endogenous stimulus & 1.06 & 0.35 \\
cell death & 0.93 & 1.90 \\
death & 0.71 & 0.33 \\
response to external stimulus & 0.71 & 0.33 \\
DNA metabolic process & 0.71 & 0.67 \\
response to biotic stimulus & 0.57 & 0.78 \\
reproduction & 0.49 & 1.50 \\
cellular homeostasis & 0.34 & 2.38 \\
anatomical structure morphogenesis & 0.30 & 0.38 \\
growth & 0.25 & 0.97 \\
post-embryonic development & 0.17 & 0.63 \\
cell growth & 0.15 & 1.20 \\
embryonic development & 0.12 & 0.52 \\
cell cycle & 0.10 & 1.23 \\
flower development & 0.07 & 0.50 \\
ripening & 0.07 & 0.64 \\
regulation of gene expression, epigenetic & 0.05 & 0.01 \\
Abscission & 0.02 & 0.35 \\
& 0.00 & 0.03 \\
\hline & & \\
\hline
\end{tabular}

Citrus genes are those reported here and Arabidopsis genes are those from TAIR. Data are shown as percentages.

\section{Genomic coverage of the unigenes identified}

We estimated the genomic coverage of the unigenes identified in the present work by comparing their functional distribution to that of a full sequenced plant genome. Table 3 shows the distribution of the citrus unigenes and Arabidopsis genome along the main GO functional categories in the 'Biological Process' ontology. The distribution along the main functional categories in the three different GO ontologies is showed in the Additional File 4. These results show that the different unigenes obtained are involved in many different categories covering virtually every aspect of plant biology and offer a good representation of the citrus genome.

\section{Full-length cDNA clones}

Since libraries were constructed using oligo-dT for cDNA synthesis and inserts were 5 '-end sequenced, we estimated the number of putative full-length cDNA clones generated 
by calculating the number of clones that had BLASTX matches to proteins of the reference plant Arabidopsis that included the first amino acid of the Arabidopsis protein (Table 2). A total of 3304 unigenes were identified as having putative full-length clones by this method. In most of these cases, the unigene sequence also contains additional sequence upstream of the start codon in the alignment, possibly corresponding to 5'-UTR. These putative full-length unigenes represent $63 \%$ of the total number of unigenes having matches with Arabidopsis proteins (5248 unigenes), indicating that about 3870 unigenes ( $63 \%$ of the total number of unigenes with some of the clones coming from the libraries constructed herein) are expected to have at least one full-length cDNA clone among their components. However, identification of fulllength clones using this approach is a relatively crude method, and these values must be only taken as a rough estimate.

We next investigated the efficiency of the library construction protocol with regard to the enrichment in full-length clones. The comparison with the results for the libraries not enriched in full-length clones clearly indicates that full-length libraries described here produced a considerably higher percentage of full-length unigenes ( $>40 \%$ in 14 out of 15 libraries; two of them $>60 \%$ ) (Table 2) than the other standard libraries (none above 32\%) [4]. Furthermore, full-length estimation by ESTs instead of unigene sequences emphasized the benefits of the full-length enrichment protocol. While the putative full-length ESTs in other standard libraries account for 30\% to $69 \%$ (44\% on average, subtraction libraries including a cDNA fragmentation step in their protocol were not considered, data not shown), those in our full-length libraries comprise $67 \%$ to $86 \%$ ( $77 \%$ on average) (Table 2 ).

\section{Efficiency of cDNA libraries normalization}

Most normalization strategies are based on the reaction kinetics of re-association of denatured DNA. However, not all of them are amenable to full-length cDNA approaches. The most widely used technology for normalization and substraction in large-scale gene discovery relies on the re-association of nucleic acids in amplified plasmid libraries $[22,23]$ and consequently suffers from cDNA-size cloning bias that can lead to under-representation of long cDNAs. To avoid the problems related to the amplification of libraries, Carninci et al. [18] developed a method to normalize and subtract cDNA before cloning. In that method, a biotinylated driver (usually an aliquot of the mRNA initially used for the cDNA library preparation) is employed to detect and eliminate abundant cDNAs. However, this method has several drawbacks as it requires high quantities of starting poly $\left(\mathrm{A}^{+}\right) \mathrm{RNA}$ and is time-consuming [25].
Among the different methods employed to separate the normalized ss-cDNA fraction we chose normalization with the thermostable DSN nuclease [24,25]. It displays a strong preference for cleaving double-stranded DNA and DNA in DNA-RNA hybrid duplexes compared with ssDNA and ss-RNA, irrespective of sequence length. Due to the thermostable properties of the DSN enzyme, the degradation of the double-stranded fraction is carried out at the same temperature as the re-naturation of cDNA. This helps to avoid a non-specific hybridization of cDNA during the DSN treatment and, hence, the loss of transcripts which are prone to the formation of secondary structures.

On the other hand, each cDNA population requires a specific normalization treatment (different quantities of DSN enzyme). Those normalized cDNAs were then subjected to amplification by PCR in order to identify the population that had undergone the best normalization. Aliquots of the PCR reaction were extracted at different amplification cycles and tested by electrophoresis to identify the samples showing a good normalization profile (Additional File 5). The profile of an efficiently normalized and amplified cDNA was one whose overall signal intensity of a smear (at its plateau) was similar to that shown for the control, but does not contain distinguishable bands nor shows smear in the high-molecular-weight region of the gel (> $4.5 \mathrm{~kb})$. Finally, a virtual northern [34] was carried out to estimate the relative concentration of a highly abundant clone in both the non-normalized and the normalized cDNA populations obtained from the second run of amplification (Additional File 5C and 5D). The clone C32009H03 from the contig aCL11 contig11, whose consensus sequence shows similarity with the family of lectinrelated protein kinases, was selected as probe because it was present at high copy number in the equivalent fulllength non-normalized cDNA library RVDevelop1, revealing the high expression of the corresponding citrus gene. Equal amounts of normalized and non-normalized cDNA samples were electrophoresed and transferred to a nitrocellulose membrane. The reduction in the abundance of the frequent clone, used as a radioactive probe, in the normalized sample became evident since much lower signal intensity was detected when compared to that observed in the non-normalized cDNA.

In summary, 4 out of the 15 full-length cDNA libraries were normalized using this approach. Overall, the redundancy of these libraries is lower than that of non-normalized libraries (Table 2). Furthermore, when the distribution of the number of ESTs per contig is compared, normalized libraries show a higher proportion of contigs with a low number of ESTs and a lower proportion of contigs represented by a high number of ESTs (Additional File 3). Finally, the new citrus ESTs collection added almost 2000 new genes not previously represented in the 
Citrus HarvEST database, which already contains 229,570 ESTs. These results show a good efficiency for the normalization step and demonstrate the convenience of this approach to improve the efficacy of the sequencing effort at isolating new and/or low expressed transcripts in the EST collections.

\section{Functional analysis of citrus genes by transformation of Arabidopsis plants}

Arabidopsis is the reference system for plant biologists [35] due to several characteristics, such as the availably of its full-genome sequence and simplicity of transformation, which makes it an excellent system for functional analysis of heterologous genes. For the ectopic expression of citrus genes in Arabidopsis, we chose the destination vector pMDC32 designed by Curtis et al. [31]. The backbone of this vector is derived from the pCambia series of binary vectors for Agrobacterium-mediated plant transformation. The Gateway cassette is adjacent to the dual 35S CaMV promoter, so the expression of the heterologous genes is under the control of this strong promoter.

To validate the system implemented in our cDNA collection for rapid functional characterization of citrus genes, we selected a citrus member of the SEPALLATA gene family of transcription factors with MADS-box domain. Plant MADS-box gene family participates in the determination of floral organ identity. Among them, the SEPALLATA are a class of MAD-box genes with a role as floral homeotic genes that are required for the development of petals, stamens and carpels [36]. In Arabidopsis, the SEPALLATA gene family is composed of four members (SEP1 to SEP4). Triple mutant Arabidopsis plants lacking the activity of three SEP1/2/3 genes produce flowers in which all organs develop as sepals [36]. Moreover, over-expression of these genes provokes alterations in organ identity as well as early flowering and curly leaves [37]. In addition, other SEPALLATA genes from different species have been expressed in Arabidopsis. For example, overexpression of either lily LMADS3 or wheat TaMADS1, both orthologs of Arabidopsis SEP3, causes early flowering after producing only four or five curly rosette leaves [38,39]. Thus SEP gene function is easy to score by ectopic expression in a validated heterologous system, like Arabidopsis.

To express a citrus SEP gene in Arabidopsis, we first searched our citrus database for a full-length clone showing the highest homology to SEPALLATA genes. In alignment assays, the clone C32006D10, that had been isolated from the cDNA library RVDevelop1, showed a high degree of sequence identity (75\%) with the Arabidopsis gene SEP3. The C32006D10 clone was completely sequenced. It corresponds to a 999-nt transcript, with a deduced protein sequence of 244 amino acids with a molecular weight of $27.8 \mathrm{kDa}$ (Figure 1 and Additional
File 6). Aminoacid sequence also showed a very high sequence similarity to Arabidopsis SEP proteins (Figure 1A), indicating that the C32006D10 clone corresponds to the citrus orthologs of the Arabidopsis SEP3 (Figure 1B). Thus, the corresponding gene was named CitrSEP. More recently, five citrus SEP genes (CitMADS1/3/5/6/8) have been isolated and characterized [40]. Although CitrSEP is almost identical to CitMADS3, they differ in the first 4 aminoacid residues (data not shown), with the aminoend sequence of CitrSEP (MGRG-) being identical to all Arabidopsis SEP genes (Figure 1A), unlike the distinct Nterminal sequence of CitMADS3, MARGG-. Thus, CitrSEP and CitMADS3 appear to correspond to different but highly related citrus genes.

The CitrSEP cDNA clone was then transferred to the destination vector pMDC32 by means of LR clonase reaction as detailed in Methods. This clone was introduced in Arabidopsis, and several hygromycin-resistant homozygous lines were selected. Figure 2 shows the expression of CitrSEP gene in transgenic lines L120-5 and L120-9, which displayed the highest expression levels and were thus selected for further analysis. Next, we tested the expression of the endogenous SEP genes, as well as CitrSEP, by qRT-PCR with gene-specific primers. Interestingly, along with the overexpression of the CitrSEP gene, the endogenous SEP3 was also strongly upregulated in these lines (Figure 2), while the other three SEP genes were also affected but to a lesser extent (Additional File 7), suggesting a positive feedback on its regulation whose characterization goes beyond the scope of this work. Recently, it has been reported that SEP3 interacts with other MADS-box proteins, including other SEP, to form multimeric protein complexes, suggesting a role as mediator of higher-order complex formation [41]. Transgenic plants were grown to maturity and their phenotypes were scored. Both lines bolted earlier than control plants, both in long and short days (Figure 3A). In addition, leaves of transgenic lines showed curly leaves (Figure 3B). All of these phenotypes were indistinguishable from those already reported for the overexpression of SEP genes in Arabidopsis, suggesting that CitrSEP is indeed a functional homolog of SEP3 in citrus.

The availability of an easy and efficient transfer method enabling subcloning of full-length cDNAs into expression vectors allows for the rapid analysis of gene function in citrus. Although we fully sequenced the CitrSEP clone as a proof of concept, the system implemented in our EST collection bypasses the need for cDNA sequencing, as clones can be rapidly transferred regardless of their sequence information, without restriction enzyme digestion utilized in classical cloning methods. We believe that this collection can provide an enormous advantage for gene validation in citrus. Furthermore, the enrichment of full- 

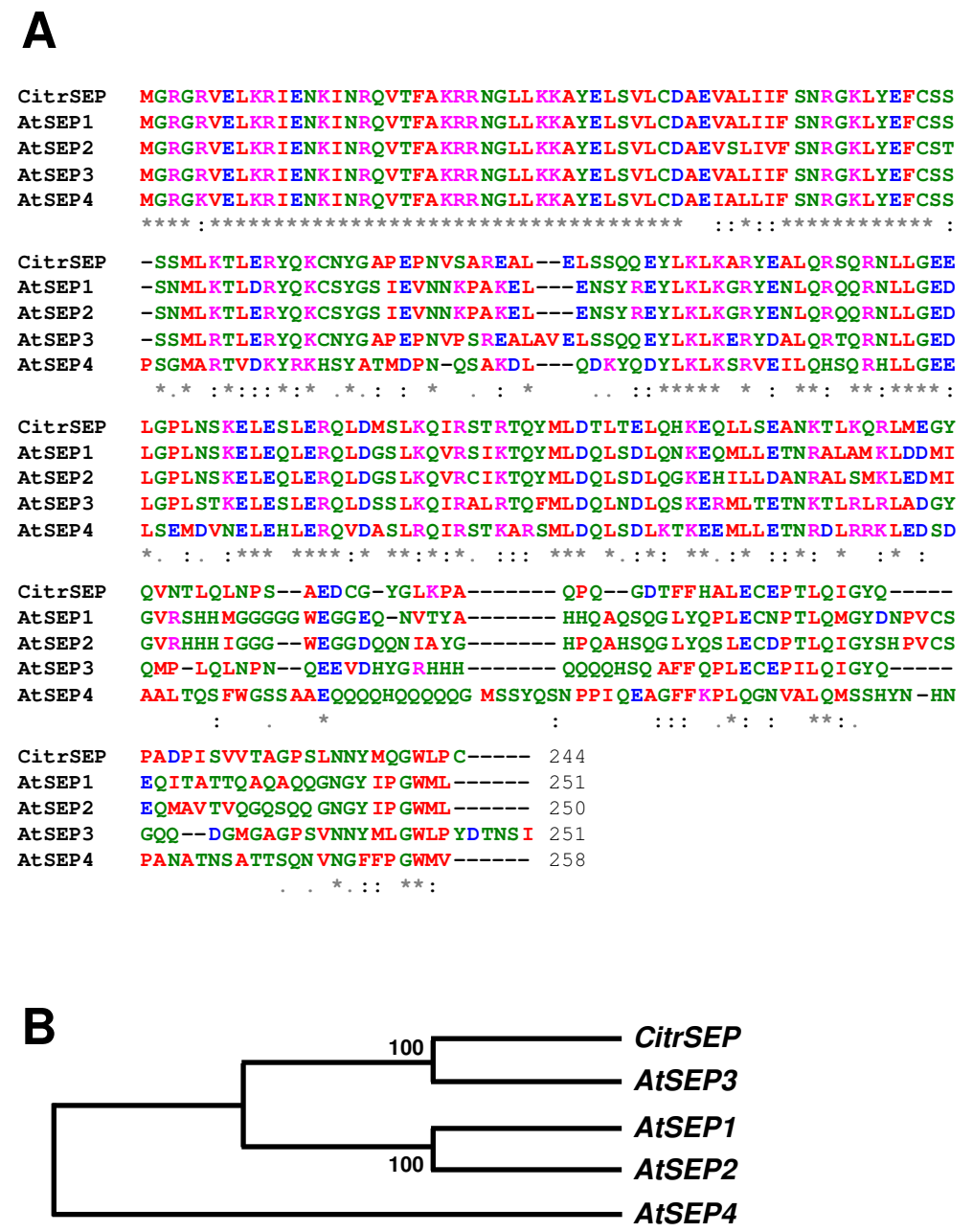

\section{Figure I}

Sequence comparison of CitrSEP and Arabidopsis orthologues. A, Protein sequence alignment of CitrSEP with Arabidopsis orthologues SEPI (At5g15800), SEP2 (At3g023 I0), SEP3 (Atlg24260), and SEP4 (At2g037l0). B, Phylogenetical tree of the aminoacid sequences of CitrSEP and the four Arabidopsis SEP genes, constructed with the ClustalW program http:// www.ebi.ac.uk/Tools/clustalw2/index.html.

length clones facilitates the task of genome annotation once the whole-genome sequence becomes available in the near future. The low percentage of redundancy among the clones isolated so far guarantees that many other genes can be successfully identified in new rounds of clone selection and sequencing from these libraries.

\section{Conclusion}

We isolated a new set of 10,898 high-quality ESTs representing 6142 different genes from 15 normalized and non-normalized cDNA libraries, using an integrated methodology. These sequences provided 2113 new citrus ESTs, representing 1831 unigenes, to the collection of citrus genes available in the public databases. Our collection shows enhanced enrichment for full-length transcripts thus facilitating downstream functional analysis of newly discovered genes. For this purpose, citrus cDNAs were introduced in a Gateway-based cloning vector for rapid high-throughput functional analysis of genes in planta. As a proof of concept of the genomic tool generated, expression in Arabidopsis of the citrus SEP3 homologue, CitrSEP, was shown to lead to early flowering, along with other phenotypes mimicking the over-expression of the Arabidopsis SEPALLATA genes. These findings suggest that the SEP gene family performs similar roles in distantly related plant species, citrus and Arabidopsis, and demonstrate the utility of the new full-length cDNA clone collection for the analysis of gene function. 
A

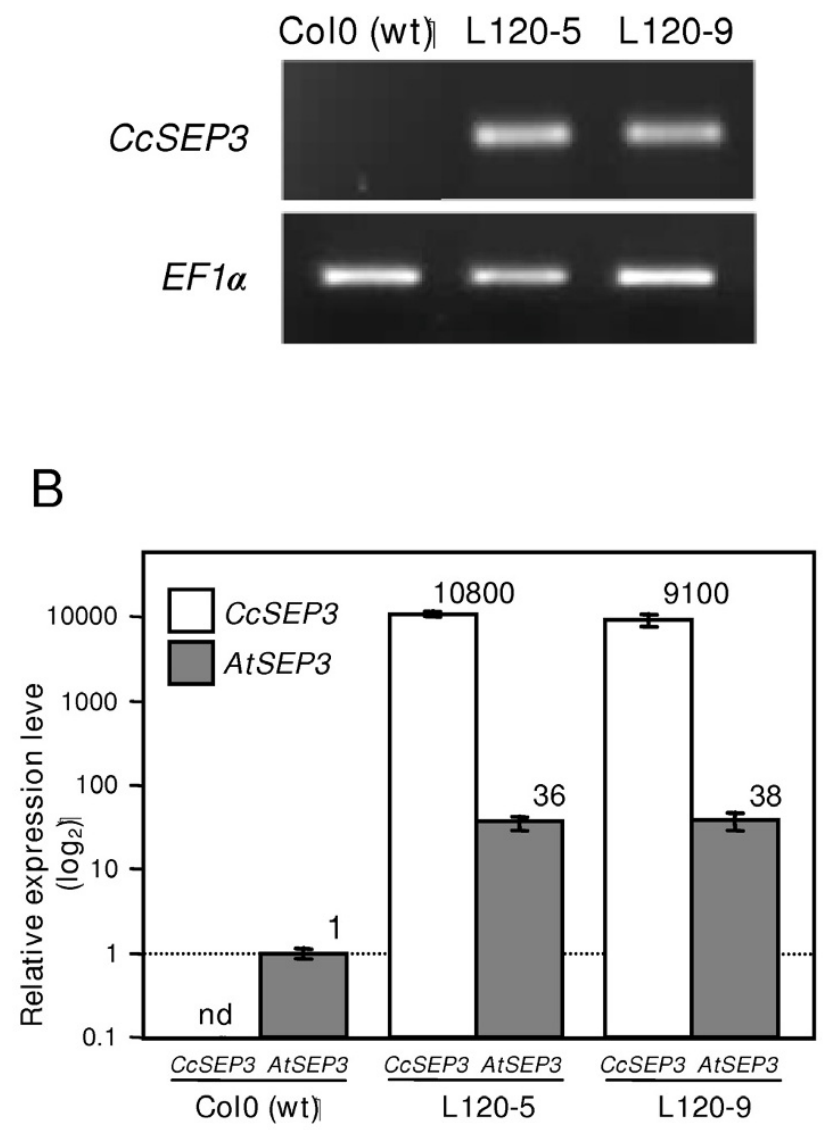

Figure 2

Expression analysis of transgenic Arabidopsis plants that overexpress the CitrSEP gene. A, Semi-quantitative RT-PCR analysis of 12-day old untransformed Col-0 and transgenic lines LI20-5 and LI20-9. B, QRT-PCR of CitrSEP and endogenous SEP3 in transgenic lines. Expression was normalized to the expression of the constitutive EF-I- $\alpha$ gene, and then to the expression in Col-0 plants. For normalization purposes, the detection level of our qRT-PCR analysis was used as an estimate of CitrSEP expression in Col-0. Expression level is indicated in the plot. nd, not detected.

\section{Methods}

\section{Plant material and treatments}

Citrus leaves, shoots, roots, developing flowers, and fruits were harvested from different citrus species (C. aurantium, C. reshni, C. clementina (var. Clemenules), C. macrophylla, and $C$. medica) subjected to different biotic or abiotic stresses or at different developmental stages (Table 1). Adult trees were grown under field conditions at the IVIA (Moncada-Valencia, Spain). Young trees (6-month-old seedlings) were grown in pots $(20 \mathrm{~cm}$ in diameter $\times 30 \mathrm{~cm}$

\section{A}
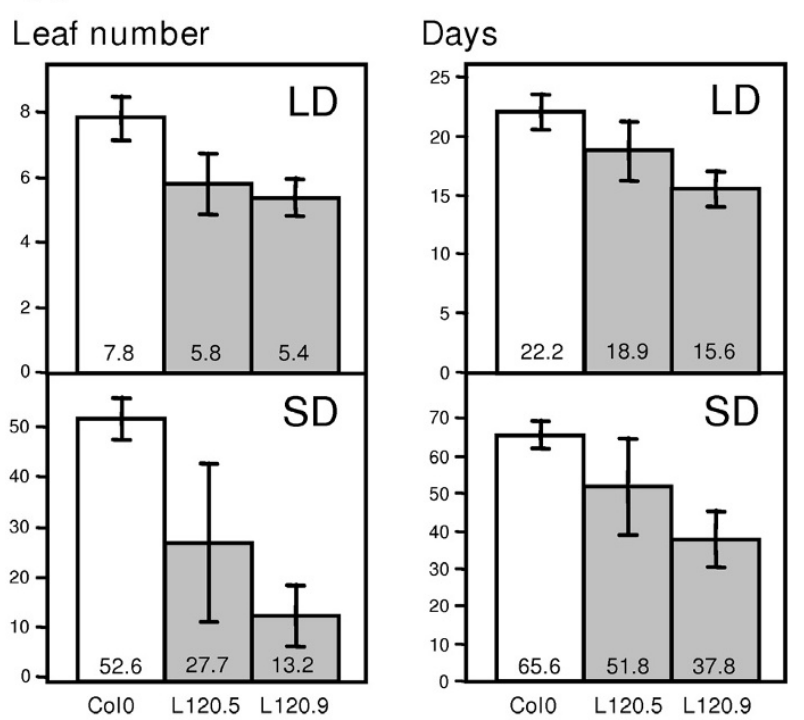

B
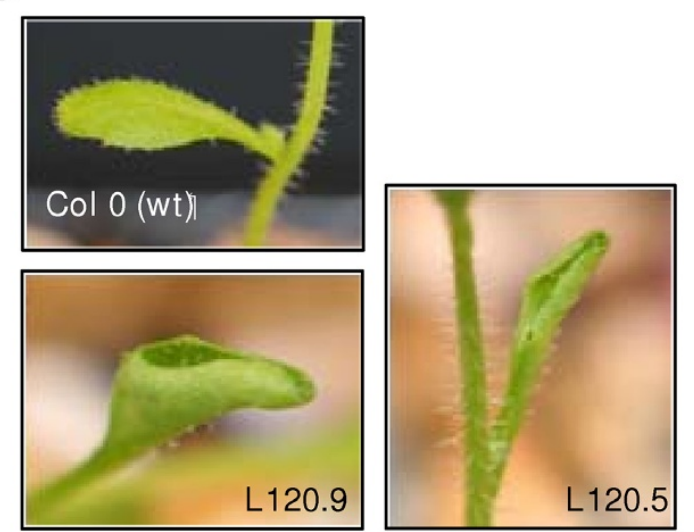

\section{Figure 3}

Overexpression of CitrSEP provokes early flowering in transgenic lines. A, quantification of flowering time in untransformed Col-0 and transgenic LI 20-5 and LI 20-9 lines. Leaf number (left panels) or days (right panels) upon flowering are as indicated. B, Images of the curly leaf phenotype in transgenic lines.

in height) in a greenhouse under natural light at $27^{\circ} \mathrm{C}$ and $60 \%$ humidity.

For the water stress treatment, plants were transplanted to pots with dried substrate and tissues were collected at 0, 5, 10 and 24 hours after the treatment. Some of the water stressed plants were watered after 24 hours and tissues were collected 2 and 12 hours later. Salt stressed plants were either watered with $200 \mathrm{mM} \mathrm{NaCl}(-1.04 \mathrm{MPa})$ and tissues were collected at 3 hours, 24 hours and 4 days, or 
were watered with $30 \mathrm{mM}(-0.15 \mathrm{MPa}) \mathrm{NaCl}$ for 3 months and with $60 \mathrm{mM}(-0.32 \mathrm{MPa}) \mathrm{NaCl}$ for another 3 months, and tissues were collected when the treatment was brought to completion. For the iron chlorosis assay, plants were watered with an iron scavenger, and foliar tissue was collected from the second, third and fourth bolting after the treatment. For the biotic stresses, plants were infected with Citrus Tristeza Virus (CTV), Citrus Exocortis viroid (CEVd) or Hot Stunt Viroid (HSVd) by grafting plants with bark pieces (containing a stem bud) from infected plants at the IVIA (Instituto Valenciano de Investigaciones Agrarias Moncada, Valencia, Spain), and tissues were collected once the symptoms appeared. For the infection with the oomycete Phytophthora citrophthora, the plants were transferred to containers with a solution of zoospores. Once the infection (foot rot) developed, roots were collected. Some postharvest stresses, such as cold stress or the infection with the fungus Penicillium digitatum, were assayed in harvested mature fruits. For the cold treatment, fruits were stored at $2{ }^{\circ} \mathrm{C}$ and the tissues were collected at different times, from hours to several months. Harvested mature fruits were infected with spores of $P$. digitatum following wounding of the fruit surface and kept under high humidity conditions for 8, 12 and 24 hours. For developmental studies, different tissues were taken at various developmental stages: leaves (2-3, 34, 4-5, 5-6 and 6-8 cm in length); apical meristems (1-2 cm long); inflorescences (3-4, 5-6 and 8-9 cm in length); unpollinated ovaries (closed floral bud, petal fall, anthesis, and senescent); and fruits (1, 3, 7 and 14 days after treatment of flowers with $\left.\mathrm{GA}_{3}\right)$.

Wild-type and transgenic Arabidopsis thaliana plants (Col0 ) were grown in chambers under $16 \mathrm{~h}$ light - $8 \mathrm{~h}$ dark regime, at $22^{\circ} \mathrm{C}$. Seeds were surface-sterilized and selected in Murashige and Skoog (MS) media.

\section{RNA isolation for library construction}

Total RNA was extracted from different organs and tissues by phenol separation and $\mathrm{LiCl}$ precipitation according to Bugos et al. [42] with minor modifications. Poly $\left(\mathrm{A}^{+}\right) \mathrm{RNA}$ was isolated from total RNA using Oligotex mRNA kit (Qiagen).

\section{Development of a Gateway-based cDNA cloning vector} Prior to the construction of the full-length enriched library we developed a cloning vector (pENTR-SfiI) allowing for both effective directional cloning by taking advantage of the nonsymmetrical cleavage of the SfiI restriction enzyme and for the ease of subcloning provided by the Gateway System. For that purpose, we performed several modifications in the commercially available Invitrogen's pENTR1A vector. Briefly, pENTR1A plasmid was digested with EcoRI and XhoI to remove the $c c d B$ gene. The pENTR$S f i$ vector was obtained by ligation of a $S f i$ adaptor, con- taining two different recognition sequences for the SfiI restriction enzyme ( $S f i \mathrm{IA}$ and $S f i \mathrm{IB}$, underlined), to the digested vector arms. The adaptor was prepared by annealing the oligonucleotides pENTR-SfiI-F (5'AATTCGGCCATTATGGCCTGCAGGATCCGGCCGCCTCGGCC-3') and pENTR-SfiI-R (5'TCGAGGCCGAGGCGGCCGGATCCTGCAGGCCATAATGGCCG-3') after heating for 10 minutes at $70^{\circ} \mathrm{C}$ and slowly cooling at RT. The SfiI recognition sites in the oligos are underlined. EcoRI and XhoI sites were restored in the pENTR-Sfil vector. Ligation product was used to transform competent JM110 E. coli cells. Although there is no recognition DNA sequence in our $S$ fiI recognition sites for Dam or Dcm methylation, we observed that digestion with SfiI was much more efficient in JM110 cells, which are deficient in Dam and Dcm methylation, than in the conventional DH5 $\alpha$ competent cells. Prior to its use as cloning vector, the pENTR-SfiI was digested with $S f i$ I (Roche) for 4 hours at $50^{\circ} \mathrm{C}$ and dephosphorylated by incubation with shrimp alkaline phosphatase (USB) at $37^{\circ} \mathrm{C}$ for 90 minutes.

\section{Construction of full-length enriched cDNA libraries}

Additional File 1 outlines the methodology for cDNA construction followed in this work. For the construction of the full-length enriched cDNA libraries we used the SMART $^{\mathrm{TM}}$ technology with minor modifications [6]. The BD SMART ${ }^{\mathrm{TM}}$ PCR cDNA Synthesis kit (BD Biosciences) was used for the synthesis of cDNA starting from $0.5 \mu \mathrm{g}$ of poly $\left(\mathrm{A}^{+}\right) \mathrm{RNA}$. The first-strand cDNA synthesis, $\mathrm{dC}$ tailing and template switching and extension by RT were performed according to the instructions of the manufacturer. However, the primers used in the reaction were the $\mathrm{BD}$ Biosciences' oligonucleotides SMART IV (5'AAGCAGTGGTATCAACGCAGAGTGGCCATTAT-

GGCCGGG-3'), containing the SfiIA recognition site (underlined), and the CDSIII/3' PCR primer (5'-ATTCTAGAGGCCGAGGCGGCCGACATG-d(T) $\left.{ }_{30} \mathrm{~N}_{-1} \mathrm{~N}-3^{\prime}\right)$, containing the SfiIB recognition sequence (underlined). We made 6 second-strand synthesis reactions for every cDNA library. Three reactions were used to generate the fulllength cDNA libraries described here and the other three reactions were stored to generate the normalized cDNA libraries described below. For each of the second-strand synthesis reactions, $2 \mu \mathrm{l}$ of the single stranded cDNA were amplified by PCR in a Perkin Elmer 9400 thermal cycler using the following parameters: an initial preheating at $95^{\circ} \mathrm{C}$ for $1 \mathrm{~min}$ and additional 16 cycles of $5 \mathrm{~s}$ at $95^{\circ} \mathrm{C}, 5$ $\mathrm{s}$ at $65^{\circ} \mathrm{C}$ and $6 \mathrm{~min}$ at $68^{\circ} \mathrm{C}$. The PCR mix was in accordance with the manufacturer instructions. Next, the cDNA obtained in every second-strand reaction was blunt-ended following the provided instructions. Once polished, the cDNA was digested with $60 \mathrm{u}$ of SfiI (Roche), purified using the Qiaquick PCR Purification kit (Qiagen), and electrophoresed in a $1 \times$ TAE $1 \%$ agarose gel. Fragments 
ranging between $1 \mathrm{~kb}$ and $5 \mathrm{~kb}$ were purified with the Qiaquick Gel Extraction kit. The ds-cDNA was then ready to be ligated into the modified pENTR-Sfil vector. Ligation was performed with $10 \mathrm{ng}$ of pENTR-SfiI vector and $10 \mathrm{ng}$ of cDNA, with $2 \mathrm{u}$ of T4 DNA ligase (Roche) in a final volume of $10 \mu \mathrm{l}$. The reaction was incubated at $16^{\circ} \mathrm{C}$ for 18 hours. One half of the ligation reaction was used to transform One Shot MAX Efficiency DH5 $\alpha$-T1 Competent Cells (Invitrogen), and transformed cells were selected onto LB agar plates supplemented with $50 \mu \mathrm{g} / \mathrm{ml}$ kanamycin.

\section{Normalization of CDNA and construction of normalized cDNA libraries}

For the normalization we took advantage of the properties of the Duplex-Specific Nuclease (DSN) enzyme purified from Kamchatka crab hepatopancreas (Evrogen) [24]. DSN displays a strong preference for cleaving ds DNA and DNA in DNA-RNA hybrid duplexes. The substrates of the DSN were the three ds-cDNA synthesis reactions left aside during the full-length library construction described above. Two reactions were stored before cDNA was bluntended as a control of the normalization and a third reaction was used for normalization.

Most of the normalized cDNA libraries were prepared from the same mixture of ds-cDNA previously produced to obtain the full-length cDNA libraries (Table 1 and Additional File 1). The normalization process was carried out following the protocol of a cDNA Normalization kit provided by Evrogen with some modifications, to make it suitable for the construction of our specific cDNA libraries. Purified ds-cDNA (120 ng) was mixed with $4 \mu \mathrm{l}$ of $4 \times$ hybridization buffer (200 mM Hepes, $\mathrm{pH} 7.5$ and $2 \mathrm{M}$ $\mathrm{NaCl}$ ), in a $16 \mu \mathrm{L}$-final volume, and aliquoted in 4 PCR tubes. The ds-cDNA was denatured by incubating the tubes at $98^{\circ} \mathrm{C}$ for 2 minutes. Then, re-hybridization was performed by incubation at $68^{\circ} \mathrm{C}$ for 5 hours. Preheated DSN master buffer ( $5 \mu$ l per tube) was added and tubes were incubated at $68^{\circ} \mathrm{C}$ for additional 10 minutes. Different enzyme amounts were assayed in each tube $(1,0.5$, 0.25 and 0 Kunitz-unit). Degradation reaction was carried out for $25 \mathrm{~min}$ at $68^{\circ} \mathrm{C}$. To quench the reaction, $10 \mu \mathrm{l}$ of DSN stop solution were added to each tube followed by incubation at $68^{\circ} \mathrm{C}$ for 5 minutes. Reaction was finished by cooling down the tubes on ice, and finally $20 \mu \mathrm{l}$ of water were added to bring the final volume up to $40 \mu \mathrm{l}$ per tube.

\section{First run of amplification of the normalized cDNA}

The PCR amplifications were performed using the reagents provided in Advantage 2 PCR kit (BD Biosciences). For the first run of amplification we designed new primers suitable for maintaining the average cDNA length. Specifically, their sequences were internal and shorter than those employed in the synthesis of the ds-cDNA. As in the previous normalization step, four PCR amplifications were done individually, each of them containing $1 \mu \mathrm{l}$ of the normalized cDNA with different concentrations of DSN enzyme obtained in the previous step. The PCR master mix for all the four reaction tubes was prepared by combining the following reagents in the order shown: 39 $\mu \mathrm{l}$ of sterile water, $5 \mu \mathrm{l}$ of $10 \times$ Advantage PCR Buffer, $1 \mu \mathrm{l}$ of $50 \times$ dNTP mix, $1.5 \mu \mathrm{l}$ of primer M1-5' $10 \mu \mathrm{M}$ (5'-AAGCAGTGGTATCAACGCAGAGT-3'), $1.5 \mu \mathrm{l}$ of primer M1-3' $10 \mu \mathrm{M}$ (5'-ATTCTAGAGGCCGAGGCGG-3') and $1 \mu \mathrm{l}$ of $50 \times$ Advantage Polymerase mix. The thermal cycling reactions were carried out in a preheated $\left(95^{\circ} \mathrm{C}\right)$ Perkin-Elmer 9400 machine using the following parameters: $7 \mathrm{sec}$ at $95^{\circ} \mathrm{C}, 10 \mathrm{sec}$ at $66^{\circ} \mathrm{C}$ and $6 \mathrm{~min}$ at $72^{\circ} \mathrm{C}$. As the optimal number of cycles had to be established empirically for each cDNA library to be done, a $10 \mu \mathrm{l}$ aliquot of each PCR reaction was transferred to a clean tube after 7, 9, 11, 13, and 15 PCR cycles. At the end of this process, we obtained a series of 5 tubes from every initial PCR reaction (20 in total).

An aliquot of $5 \mu \mathrm{l}$ from each tube was electrophoresed in a TAE $1.5 \times$ agarose gel to determine the efficiency of normalization. The cDNA used in the next step was chosen according to three characteristics: 1) overall signal intensity of the smear is similar to that shown for the control (without DSN digestion) but does not contain distinguishable bands, 2) signal intensity of smear has reached its plateau, and 3 ) the cDNA smear does not exceed 4.5 $\mathrm{kb}$.

\section{Second run of amplification of the normalized cDNA}

Both the reaction that best fit in the normalization parameters and the non-normalized reaction (control) were diluted 1:10. A second run of amplification was carried out with an aliquot of $2 \mu \mathrm{l}$ from those dilutions. To increase the amount of CDNA, three reactions of amplification were performed for the normalized cDNA. The PCR master mix was prepared by combining the following reagents: $76 \mu \mathrm{l}$ of sterile water, $10 \mu \mathrm{l}$ of $10 \times$ Advantage PCR buffer, $2 \mu \mathrm{l}$ of $50 \times \mathrm{dNTP}$ mix, $4 \mu \mathrm{l}$ of primer M2-5' $10 \mu \mathrm{M}$ (5'-AAGCAGTGGTATCAACGCAG-3'), $4 \mu \mathrm{l}$ of primer M23' $10 \mu \mathrm{M}$ (5'-ATTCTAGAGGCCGAGGCG-3') and $2 \mu \mathrm{l}$ of $50 \times$ Advantage Polymerase mix. The thermal cycling reactions were carried out in a preheated $\left(95^{\circ} \mathrm{C}\right)$ Perkin-Elmer 9400 machine with 12 cycles of $7 \mathrm{sec}$ at $95^{\circ} \mathrm{C}, 10 \mathrm{sec}$ at $66^{\circ} \mathrm{C}$ and $6 \mathrm{~min}$ at $72^{\circ} \mathrm{C}$. Once finished, $300 \mu \mathrm{l}(100 \mu \mathrm{l} \times$ 3 reactions) of normalized cDNA were ready to be used in the construction of the normalized cDNA library.

\section{Last steps for the construction of the normalized cDNA library}

The next steps in the construction of the normalized cDNA library (cDNA polishing, digestion and electro- 
phoresis of digested cDNA, cDNA purification, ligation into pENTR-SfiI vector and transformation of competent E. coli cells) were identical to those described above for the construction of the full-length cDNA libraries.

\section{Virtual northern to assess the normalization efficiency}

For a better assessment of the normalization efficiency we performed a virtual northern to estimate the relative concentration of a highly abundant clone in both the nonnormalized and the normalized cDNA populations obtained from the second run of amplification. Equivalent quantities of cDNA corresponding to the non-normalized and normalized samples subjected to the second run of amplification were electrophoresed in a TAE $1.5 \times$ gel, transferred to a nitrocellulose membrane, followed by a standard Southern blot analysis. A PCR was performed to amplify the C32009H03 clone, which was previously identified as highly abundant in our RVDevelop1 library, using vector oligos (pENTR-F: 5'-GGCTTTAAAGGAACCAATTCA-3' and pENTR-R: 5'-GCAATGCTTTCTTATAATGCCAAC-3'). Ten nanograms of this PCR fragment were used in a labeling reaction with [ $\left.\alpha-{ }^{32} \mathrm{P}\right] \mathrm{dCTP}$ using Ready to Go DNA labeling kit (Amersham Bioscience), and reaction was purified from unincorporated nucleotides using probe purification columns (NucTrap, Stratagene, or Quick Spin, Roche). The DNA blot membrane was hybridized according to the protocol described by Church and Gilbert [43].

\section{EST collection and sequencing}

Colonies were randomly-selected from LB agar plates supplemented with $50 \mu \mathrm{g} / \mathrm{ml}$ kanamycin. After manual picking, colonies were grown overnight in standard LBkanamycin media, and plasmids were isolated by alkaline lysis method using PerfectPrep (Eppendorf) or Montage (Millipore) kits. In addition, selected clones were stored at $-80^{\circ} \mathrm{C}$ as glycerol stocks. Sequencing reactions were carried out from the $5^{\prime}$ end of the CDNA insert, with the pENTR-F oligo (5'-GGCTTTAAAGGAACCAATTCA-3'), using an ABI 3100 capillary automatic sequencer (Applied Biosystems) with fluorescent dye terminator technology.

\section{EST preprocessing and assembly}

EST preprocessing and assembly was performed by using EST2uni, an open, parallel software package for EST analysis and database creation http://bioinf.comav.upv.es/ est2uni[44]. EST2uni is a completely automated computer pipeline capable of converting, using the standard EST analysis tools described below, a group of input sequence trace files in a highly structured and annotated EST database with a user-oriented web interface for efficient data mining. All of the data generated by the pipeline were stored in a web-searchable MySQL database http://bio info.ibmcp.upv.es/genomics/cfgp_fl/login.php. Base calling and quality scores assignment were made with Phred
[45] using default parameters. Low quality and cloning vector trimming was performed by Lucy [46]. Contaminant vector sequences were detected and removed by SeqClean http://compbio.dfci.harvard.edu/tgi/software using the NCBI vector database UniVec http:// www.ncbi.nlm.nih.gov/VecScreen/UniVec.html. Repeat elements and low complexity region masking were done with RepeatMasker http://www.repeatmasker.org and SeqClean http://compbio.dfci.harvard.edu/tgi/software, respectively. After cleaning, sequences shorter than 100 nucleotides were discarded. Clean, high-quality EST sequences obtained in the pre-processing step were then assembled in contigs and singletons to obtain a nonredundant unigene set using TGICL http://comp bio.dfci.harvard.edu/tgi/software with default parameters. ESTs generated in this study were assembled together with the rest of ESTs obtained in the whole CFGP http:// bioinfo.ibmcp.upv.es/genomics/cfgpDB in order to improve the quality of the assembly.

To estimate the number of new ESTs and unigenes generated in this work, we compared the new citrus ESTs and unigenes with the 229,570 Citrus ESTs in the HarvEST database, version 1.25, as of June 9th 2009 http://har vest.ucr.edu/, using BLASTN and Perl scripts. An EST is considered as new if it has at least $25 \%$ of sequence with less than $95 \%$ of identity to any other EST or unigene in the HarvEST collection.

\section{Functional annotation of unigenes}

Unigene functional annotation was also done by using the EST2uni software package. As a part of the whole analysis, EST2uni carried out BLASTX against the UniRef90 non-redundant protein database http://www.ebi.ac.uk/ uniref[47] and the full set of Arabidopsis proteins provided by The Arabidopsis Information Resource (TAIR) http://www.arabidopsis.org using default parameters and arbitrary non-stringent threshold of $10^{-5}$ for E-value. Unigenes were annotated with the description of the most similar UniRef90 cluster of proteins or, when no significantly similar UniRef90 cluster was found, with the description of the most similar Arabidopsis protein, if any. Unigenes were annotated as highly similar to the first BLAST hit when the E-value was lower than $10^{-15}$. BLASTX hits with an E-value higher than $10^{-10}$ were not considered for annotation. Gene Ontology (GO) annotation of the Arabidopsis most similar protein was used for GO annotation of the citrus unigenes. Functional motifs were also identified by using a HMMER search [48] against the Pfam database http://pfam.janelia.org[49].

\section{Isolation and sequencing of a full-length CitrSEP clone}

Clone C32006D10 (CitrSEP), with homology to the Arabidopsis gene SEP3 of the MADS-box gene family, was selected. An aliquot ( $1 \mu \mathrm{l})$ of the DNA prep was subjected 
to PCR amplification using the vector oligos pENTR-F and pENTR-R (see above), and the PCR product was fully sequenced using internal oligos.

\section{Cloning into Gateway destination vectors}

The transfer of the cDNA clone CitrSEP from the pENTR$S f i$ to the Gateway destination vector pMDC32 was performed using the LR clonase kit (Invitrogen). The reaction mix was prepared by combining $2 \mu \mathrm{g}$ of plasmid C32006D10, $2 \mu \mathrm{g}$ of pMDC32 plasmid, $4 \mu \mathrm{l}$ of $5 \times$ LR clonase and $8 \mu$ l of reaction buffer, and the sample was then incubated at $25^{\circ} \mathrm{C}$ for $60 \mathrm{~min}$. The reaction was then treated with $2 \mu \mathrm{l}$ of proteinase $\mathrm{K}$ by incubation at $37^{\circ} \mathrm{C}$ for 10 minutes. An aliquot $(1 \mu \mathrm{l})$ from the recombination reaction was used to transform One Shot MAX Efficiency DH5 $\alpha$-T1 Competent Cells (Invitrogen) according to the manufacturer instructions, and cells were selected on LB agar plates containing $50 \mu \mathrm{g} / \mathrm{ml}$ of kanamycin. Selection of positive clones was carried out by PCR analysis.

\section{Transformation of Arabidopsis plants}

The binary plasmid pMDC32 carrying the citrus clone C32006D10 was used to transform Agrobacterium tumefaciens GV3101 C58C1 Rifr (pMP90) [50] by electroporation using a Gene-Pulse apparatus (Bio-Rad). Col-0 Arabidopsis plants were transformed by the floral dip method [51]. T1 seeds were plated on MS media supplemented with $50 \mu \mathrm{g} / \mathrm{mL}$ hygromycin for selection of transformants and $500 \mu \mathrm{g} / \mathrm{mL}$ vancomycin to limit the growth of Agrobacterium. T2 seeds were collected and homozygous lines were selected based on hygromycin resistance of the T3 progeny. Expression of the CitrSEP gene in seedlings was assayed by semi-quantitative and quantitative qRT-PCR, and homozygous lines showing highest CitrSEP expression were selected and used for functional characterization.

\section{Semi-quantitative RT-PCR and qRT-PCR analysis of gene expression}

Total RNA was extracted from frozen rosette leaves using the RNeasy Plant Mini kit (Qiagen). Genomic DNA was eliminated during RNA purification by treatment with 50 units of DNaseI (RNase-free DNase set (Qiagen) for 15 min at room temperature. Two micrograms of total RNA were used to synthesize first strand CDNA, using the SuperScript $^{\mathrm{TM}}$ First-Strand Synthesis System for RT-PCR (Invitrogen Life Technologies). cDNA synthesis reactions were finally diluted in a volume of $80 \mu \mathrm{L}$.

For semi-quantitative RT-PCR, the ELONGATION FACTOR 1- $\alpha(E F-1-\alpha)$ gene (At1g07940) was used as an internal control for quantification. Primers were used to amplify a 532 bp fragment from EF-1- $\alpha$ cDNA and a 535 bp fragment from CitrSEP cDNA. cDNA solution $(1 \mu \mathrm{L})$ was used in PCR reactions (50 $\mathrm{L}$ final volume) in the presence of $0.6 \mu \mathrm{M}$ of each clone-specific primer and 2.6 units of Expand High Fidelity enzyme (Roche). PCR reaction conditions were $5 \mathrm{~min}$ at $95^{\circ} \mathrm{C}$, followed by 25 cycles of $30 \mathrm{~s}$ at $95^{\circ} \mathrm{C}, 45 \mathrm{~s}$ at $60^{\circ} \mathrm{C}$ and $45 \mathrm{~s}$ at $72^{\circ} \mathrm{C}$, and a final extension of $10 \mathrm{~min}$ at $72^{\circ} \mathrm{C}$. The products were detected in a $1 \%(\mathrm{v} / \mathrm{v})$ agarose $1 \times$ TAE gel and stained with ethidium bromide before quantifying using the Gene Snap (SynGene) program.

qRT-PCR was carried out using the SYBR $^{\circledR}$ GREEN PCR Master mix (Applied Biosystems) in an ABI PRISM 7000 Sequence Detection System (Applied Biosystems). Final reaction volume was $20 \mu \mathrm{L}$, with $1 \mu \mathrm{L}$ of cDNA, $10 \mu \mathrm{L}$ of SYBR $^{\circledR}$ GREEN PCR Master mix, and $9 \mu \mathrm{L}$ of primer mixture, containing $0.66 \mu \mathrm{M}$ of each primer. The PCR program consisted of an initial incubation of $2 \mathrm{~min}$ at $50^{\circ} \mathrm{C}$ followed by a de-naturation at $95^{\circ} \mathrm{C}$ for $10 \mathrm{~min}$, and 40 cycles of amplification of 15 seconds at $95^{\circ} \mathrm{C}$ and $1 \mathrm{~min}$ at $60^{\circ} \mathrm{C}$. Each sample was assayed in triplicates, and each experiment was repeated at least twice. Expression levels were calculated relative to the constitutively expressed gene EF-1- $\alpha$. Normalization was carried out using the $\Delta \Delta \mathrm{Ct}$ method (Applied Biosystems), where $\Delta \mathrm{Ct}$ was calculated for each sample as the difference between $\mathrm{Ct}$ of the CitrSEP gene and Ct of EF-1- $\alpha$, and final relative expression level was determined as inverse of $\log _{2}$ of Ct $(S E P)$ Ct $(E F-1-\alpha)$. Primers used are listed in Additional File 8.

\section{Authors' contributions}

MCM set-up the protocols for library construction, cDNA cloning and sequencing, generated the cloning vector, and performed most of the cDNA library construction. MCM, $\mathrm{RA}$, and SA carried out cDNA clone isolation and sequencing. RA and HA carried out Arabidopsis transformation and isolation of homozygous transgenic lines. HA performed all phenotypic and molecular analysis of transgenic plants. JF performed the bioinformatics work. VC directed the Spanish Citrus Genomics Project. MAPA conceived the work. MAPA and MCM wrote the manuscript. All authors read and approved this manuscript.

\section{Additional material}

\footnotetext{
Additional File 1

Scheme for the synthesis of cDNA and generation of full-length and normalized libraries. This file contains a figure schematically showing the approach employed in this study for the generation of citrus normalized full-length cDNA libraries, combining the SMART ${ }^{\mathrm{TM}}$ method to generate full-length cDNAs, the thermostable enzyme DSN to normalize cDNA populations, and the Gateway technology.

Click here for file

[http://www.biomedcentral.com/content/supplementary/14712164-10-428-S1.pdf]
} 


\section{Additional File 2}

Analysis of ESTs. This file contains figures showing details about the ESTs obtained. A, Distribution of EST length. B, Distribution of EST number per contig.

Click here for file

[http://www.biomedcentral.com/content/supplementary/1471-

2164-10-428-S2.ppt]

\section{Additional File 3}

List of the new 2113 ESTs, corresponding to 1831 new unigenes, generated. The table contains a list of the new ESTs generated not previously included in HarvEST. The corresponding unigenes and the three Gene Ontology classifications (Biological Process, Cellular Component, and Molecular Function) are indicated.

Click here for file

[http://www.biomedcentral.com/content/supplementary/14712164-10-428-S3.xls]

\section{Additional File 4}

Distribution of citrus and Arabidopsis genes according to the three GO categories. This file contains a table showing percentages of genes in the different categories of the three Gene Ontology classifications (Biological Process, Cellular Component, and Molecular Function). Citrus genes are those reported in this work, and Arabidopsis genes are those from TAIR. Click here for file

[http://www.biomedcentral.com/content/supplementary/14712164-10-428-S4.doc]

\section{Additional File 5}

Evaluation of the efficiency of normalization of cDNA libraries. This file contains figures showing results demonstrating the efficiency of the approach used for normalization of cDNA libraries. A, Gel electrophoresis analysis of $5 \mu \mathrm{l}$ aliquots from the first amplification of the normalized cDNA taken at different PCR cycles. B, Gel electrophoresis analysis of the normalized cDNA utilized in the construction of the normalized cDNA library RVDevelopN. C, Gel electrophoresis analysis of a non-normalized cDNA population (left) and a normalized cDNA population (right) from the same RNA sample. D, Virtual northern of the cDNA smear blotted and hybridized with the highly abundant clone C32009H03.

Click here for file

[http://www.biomedcentral.com/content/supplementary/14712164-10-428-S5.ppt]

\section{Additional File 6}

Sequence of the full-length clone C32006D10. This file contains cDNA and deduced amino acid sequence of the full-length clone C32006D10 from the cDNA library RVDevelop1 encoding a MADS-box gene CitrSEP from citrus, a homologue of the Arabidopsis AGL9 or SEP3(At1g24260).

Click here for file

[http://www.biomedcentral.com/content/supplementary/14712164-10-428-S6.doc]

\section{Additional File 7}

Expression analysis of transgenic Arabidopsis plants that overexpress the CitrSEP gene. This file shows expression of CitrSEP and four endogenous SEPALLATA genes analyzed by $q R T-P C R$. Expression was normalized to the expression of the constitutive EF-1- $\alpha$ gene and then to the expression in Col-0 plants. For normalization purposes, the detection level of our qRT-PCR analysis was used as an estimate of the CitrSEP expression in Col-0. Expression level is indicated in the plot. nd, not detected. Click here for file

[http://www.biomedcentral.com/content/supplementary/14712164-10-428-S7.ppt]

\section{Additional File 8}

Oligonucleotides used for gene expression by RT-PCR. This file contains a table with the sequence of oligonucleotides used for RT-PCR assays. Click here for file

[http://www.biomedcentral.com/content/supplementary/14712164-10-428-S8.doc]

\section{Acknowledgements}

We would like to acknowledge all investigators who participated in the generation of the plant materials used for RNA extraction and cDNA library construction from the Instituto Valenciano de Investigaciones Agrarias (Generalitat Valenciana), the Instituto de Biologia Molecular y Celular de Plantas (Universidad Politecnica de Valencia and Consejo Superior de Investigaciones Cientificas), and the Instituto de Agroquimica y Tecnologia de Alimentos (Consejo Superior de Investigaciones Cientificas). We thank Dr J. Gadea for critical reading of the manuscript; and Ms. M.A. MartínezGodoy for excellent technical assistance.

This work was funded by grants from the Spanish MEC GEN200I-4885CO5-0I and GEN200I-4885-CO5-02.

\section{References}

I. Talon M, Gmitter FG: Citrus Genomics. Int J Plant Genom 2008, 2008:52836I.

2. Adams MD, Kelley JM, Gocayne JD, Dubnick M, Polymeropoulos MH, Xiao H, Merril CR, Wu A, Olde B, Moreno RF, Kerlavage AR, McCombie WR, Venter JC: Complementary DNA sequencing: expressed sequence tags and human genome project. Science 1991, 252:165I-1656.

3. Hisada S, Akihama T, Endo T, Moriguchi T, Amura M: Expressed sequence tags of citrus fruit during rapid cell development phase. J Am Soc Hort Sci 1997, I 22:808-8I 2.

4. Forment J, Gadea J, Huerta L, Abizanda L, Agusti J, Alamar S, Alos E, Andres F, Arribas R, Beltran JP, Berbel A, Blázquez MA, Brumos J, Canas LA, Cercos M, Colmenero-Flores JM, Conesa A, Estables B, Gandia M, Garcia-Martinez JL, Gimeno J, Gisbert A, Gomez G, Gonzalez-Candelas L, Granell A, Guerra J, Lafuente MT, Madueno F, Marcos JF, Marques MC, Martinez F, Martinez-Godoy MA, Miralles S, Moreno P, Navarro L, Pallas V, Perez-Amador MA, Perez-Valle J, Pons C, Rodrigo I, Rodríguez PL, Royo C, Serrano R, Soler G, Tadeo F, Talon M, Terol J, Trenor M, Vaello L, Vicente O, Vidal C, Zacarias L, Conejero V: Development of a citrus genome-wide EST collection and CDNA microarray as resources for genomic studies. Plant Mol Biol 2005, 57:375-39l.

5. Terol J, Conesa A, Colmenero JM, Cercos M, Tadeo F, Agustí J, Alós E, Andres F, Soler G, Brumos J, Iglesias DJ, Götz S, Legaz F, Argout X, Courtois B, Ollitrault P, Dossat C, Wincker P, Morillon R, Talon M: Analysis of 13000 unique citrus clusters associated with fruit quality, production and salinity tolerance. BMC Genomics 2007, 8:31.

6. Zhu YY, Machleder EM, Chenchik A, Li R, Siebert PD: Reverse transcriptase template switching: A SMART (TM) approach for 
full-length cDNA library construction. Biotechniques 200I, 30:892-897.

7. Haas BJ, Volfovsky N, Town CD, Troukhan M, Alexandrov N, Feldman KA, Flavell RB, White O, Salzberg SL: Full-length messenger RNA sequences greatly improve genome annotation. Genome Biol 2002, 3:RESEARCH0029.

8. Seki M, Narusaka M, Kamiya A, Ishida J, Satou M, Sakurai T, Nakajima M, Enju A, Akiyama K, Oono Y, Muramatsu M, Hayashizaki Y, Kawai J, Carninci P, Itoh M, Ishii Y, Arakawa T, Shibata K, Shingawa A, Shinozaki K: Functional annotation of a full-length Arabidopsis cDNA collection. Science 2002, 296: I4I-I45.

9. Castelli V, Aury JM, Jaillon O, Wincker P. Clepet C, Menard M, Cruaud C, Quétier F, Scarpelli C, Schächter V, Temple G, Caboche M, Weissenbach J, Salanoubat M: Whole genome sequence comparisons and "Full-length" cDNA sequences: a combined approach to evaluate and improve Arabidopsis genome annotation. Genome Res 2004, I4:406-4I3.

10. Nanjo T, Sakurai T, Totoki Y, Toyoda A, Nishiguchi M, Kado T, Igasaki T, Futamura N, Seki M, Sakaki Y, Shinozaki K, Shinohara K: Functional annotation of 19,84 I Populus nigra full-length enriched cDNA clones. BMC Genomics 2007, 8:448-458.

II. Das M, Harvey I, Chu LL, Sinha M, Pelletier J: Full-length cDNAs: more than just reaching the ends. Physiol Genomics 200I, 6:57-80.

12. Edery I, Chu L, Sonenberg N, Pelletier J: An efficient strategy to isolate full-length cDNAs based on an mRNA cap retention procedure (CAPture). Mol Cell Biol 1995, I5:3363-337I.

13. Maruyama K, Sugano S: Oligo-capping - a simple method to replace the cap structure of eukaryotic messenger-rnas with oligoribonucleotides. Gene 1994, I38:171-174.

14. Carninci $P$, Kvam C, Kitamura A, Ohsumi T, Okazaki $Y$, Itoh $M$, Kamiya M, Shibata K, Sasaki N, Izawa M, Muramatsu M, Hayashizaki Y, Schneider C: High-efficiency full-length cDNA cloning by biotinylated CAP trapper. Genomics 1996, 37:327-336.

15. Oh JH, Kim YS, Kim NS: An improved method for constructing a full-length enriched cDNA library using small amounts of total RNA as a starting material. Exp Mol Med 2003, 35:586-590

16. Suzuki $Y$, Sugano S: Construction of a full-length enriched and a 5 '-end enriched cDNA library using the Oligo-capping method. Methods Mol Biol 2003, $221: 73-91$.

17. Clepet C, Le Clainche I, Caboche M: Improved full-length cDNA production based on RNA tagging by T4 DNA ligase. Nucleic Acids Res 2004, 32:e6.

18. Carninci $P$, Shibata $Y$, Hayatsu N, Sugahara $Y$, Shibata $K$, Itoh $M$, Konno H, Okazaki Y, Muramatsu M, Hayashizaki Y: Normalization and subtraction of CAP-trapper-selected cDNAs to prepare full-length cDNA libraries for rapid discovery of new genes. Genome Res 2000, 10:1617-1630.

19. Suzuki Y, Yoshitomo-Nakagawa K, Maruyama K, Suyama A, Sugano S: Construction and characterization of a full length-enriched and a 5'-end-enriched cDNA library. Gene 1997, 200:149-I56.

20. Belyavsky A, Vinogradova TV, Rajewsky K: PCR-based cDNA library construction: general cDNA libraries at the level of a few cells. Nucleic Acids Res 1989, 17:2919-2932.

21. Toru M, Matsui T, Heidaran MA, Aaronson SA: An efficient directional cloning system to construct CDNA libraries containing full-length inserts at high frequency. Gene 1989, 83:137-I46.

22. Bonaldo MF, Lennon G, Soares MB: Normalization and subtraction: two approaches to facilitate gene discovery. Genome Res 1996, 6:79|-806.

23. Soares MB, Bonaldo MF, Jelene P, Su L, Lawton L, Efstratiadis A: Construction and characterization of a normalized cDNA library. Proc Natl Acad Sci USA 1994, 91 : 9228-9232.

24. Zhulidov PA, Bogdanova EA, Shcheglov AS, Vagner LL, Khaspekov GL, Kozhemyako VB, Matz MV, Meleshkevitch E, Moroz LL, Lukyanov SA, Shagin DA: Simple cDNA normalization using kamchatka crab duplex-specific nuclease. Nucleic Acids Res 2004, 32:e37.

25. Zhulidov PA, Bogdanova EA, Shcheglov AS, Shagina IA, Wagner LL, Khazpekov GL, Kozhemyako VV, Lukyanov SA, Shagin DA: A method for the preparation of normalized cDNA libraries enriched with full-length sequences. Russian J Bioorg Chem 2005, 31:170-177.

26. Anisimova VE, Rebrikov DV, Zhulidov PA, Staroverov DB, Lukyanov SA, Shcheglov AS: Renaturation, activation, and practical use of recombinant duplex-specific nuclease from Kamchatka crab. Biochem-Moscow 2006, 7 I:5 I3-5 I9.
27. Shagin DA, Lukyanov KA, Vagner LL, Matz MV: Regulation of average length of complex PCR product. Nucleic Acids Res 1999, 27:e23.

28. Earley KW, Haag JR, Pontes O, Opper K, Juehne T, Song KM, Pikaard CS: Gateway-compatible vectors for plant functional genomics and proteomics. Plant / 2006, 45:616-629.

29. Hartley JL, Temple GF, Brasch MA: DNA cloning using in vitro site-specific recombination. Genome Res 2000, 10:1788-1795.

30. Karimi M, Inzé D, Depicker A: GATEWAY ${ }^{\mathrm{TM}}$ vectors for Agrobacterium-mediated plant transformation. TRENDS Plant $\mathrm{Sci}$ 2002, 7:193-195.

31. Curtis MD, Grossniklaus U: A gateway cloning vector set for high-throughput functional analysis of genes in planta. Plant Physiol 2003, I 33:462-469.

32. Busso D, Delagoutte-Busso B, Moras D: Construction of a set Gateway-based destination vectors for high-throughput cloning and expression screening in Escherichia coli. Anal Biochem 2005, 343:313-321.

33. Martinez-Godoy MA, Mauri N, Juarez J, Marques MC, Santiago J, Forment J, Gadea J: A genome-wide $20 \mathrm{~K}$ citrus microarray for gene expression analysis. BMC Genomics 2008, 9:318.

34. Franz $O$, Bruchhaus I, Roeder T: Verification of differential gene transcription using virtual northern blotting. Nucleic Acids Res 1999, 27:e3.

35. Pang PP, Meyerowitz EM: Arabidopsis thaliana: A model system for plant molecular biology. Nature BioTechnology 1987, 5:II77-II8I.

36. Pelaz S, Ditta GS, Baumann E, Wisman E, Yanofsky MF: B and C floral organ identity functions require SEPALLATA MADS-box genes. Nature 2000, 405:200-203.

37. Pelaz S, Gustafson-Brown C, Kohalmi SE, Crosby WL, Yanofsky MF: APETALAI and SEPALLATA3 interact to promote flower development. Plant J 200I, 26:385-394.

38. Tzeng TY, Hsiao CC, Chi PJ, Yang CH: Two lily SEPALLATA-like genes cause different effects on floral formation and floral transition in Arabidopsis. Plant Physiol 2003, 133:1091-I I0I.

39. Zhao XY, Cheng Z], Zhang XS: Overexpression of TaMADSI, a SEPALLATA-like gene in wheat, causes early flowering and the abnormal development of floral organs in Arabidopsis. Planta 2006, 223:698-707.

40. Endo T, Shimada T, Fujii H, Amura M: Cloning and characterization of 5 MADS-box cDNAs isolated from citrus fruit tissue. Sci Hortic 2006, 109:315-32I.

4I. Immink RG, Tonaco IA, de Folter S, Shchennikova $A$, van $D i j k A D$, Busscher-Lange J. Borst JW, Angenent GC: SEPALLATA 3: the 'glue' for MADS box transcription factor complex formation. Genome Biol 2009, I0:R24.

42. Bugos RC, Chiang VL, Zhang XH, Campbell ER, Podila GK, Campbell WH: RNA isolation from plant tissues recalcitrant to extraction in guanidine. Biotechniques 1995, 19:734-737.

43. Church GM, Gilbert W: Genomic sequence. Proc Natl Acad Sci 1984, 81:1991-1995.

44. Forment J, Gilabert F, Robles A, Conejero V, Nuez F, Blanca JM: EST2uni: an open, parallel tool for automated EST analysis and database creation, with a data mining web interface and microarray expression data integration. BMC Bioinformatics 2008, 9:5.

45. Ewing B, Hillier L, WendI MC, Green P: Base-calling of automated sequencer traces using phred. I. Accuracy assessment. Genome Res 1998, 8:175-185.

46. Chou $\mathrm{HH}$, Holmes $\mathrm{MH}$ : DNA sequence quality trimming and vector removal. Bioinformatics 2001, 17:1093-I 104.

47. Wu CH, Apweiler R, Bairoch A, Natale DA, Barker WC, Boeckmann B, Ferro S, Gasteiger E, Huang H, Lopez R, Magrane M, Martin MJ, Mazumder R, O'Donovan C, Redaschi N, Suzek B: The Universal Protein Resource (UniProt): an expanding universe of protein information. Nucleic Acids Res 2006:DI87-191.

48. Eddy SR: Profile hidden Markov models. Bioinformatics 1998 , 14:755-763

49. Bateman A, Coin L, Durbin R, Finn RD, Hollich V, Griffiths-Jones S, Khanna A, Marshall M, Moxon S, Sonnhammer EL, Studholme DJ, Yeats C, Eddy SR: The Pfam protein families database. Nucleic Acids Res 2004, 32:DI 38-4I.

50. Koncz C, Schell J: The promoter of $T_{L}$-DNA gene 5 controls the tissue-specific expression of chimaeric genes carried by a 
novel type of Agrobacterium binary vector. Mol Gen Genet 1986, 204:383-396.

5I. Clough SJ, Bent AF: Floral dip: a simplified method for Agrobacterium-mediated transformation of Arabidopsis thaliana. Plant J 1998, 16:735-743.

Publish with Bio Med Central and every scientist can read your work free of charge

"BioMed Central will be the most significant development for disseminating the results of biomedical research in our lifetime. " Sir Paul Nurse, Cancer Research UK

Your research papers will be:

- available free of charge to the entire biomedical community

- peer reviewed and published immediately upon acceptance

- cited in PubMed and archived on PubMed Central

- yours - you keep the copyright

Submit your manuscript here:

http://www.biomedcentral.com/info/publishing_adv.asp
BioMedcentral 